\title{
Analysis on Loneliness Levels of Students in Summer School of Physical Education and Sports School
}

\section{Nahit Ozdayi ${ }^{1}$

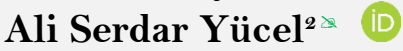 \\ Mehmet Burak Demir ${ }^{3}$}

Ballkesir University, Department of Coaching Education Balıkesir, Turkey

${ }^{2}$ Firat University, Faculty of Sports Sciences, Elazığ, Turkey

Email:alsetu_23@hotmail.com

${ }^{s}$ Directorate of National Education, Physical Education Teacher, Elazı̆g, Turkey

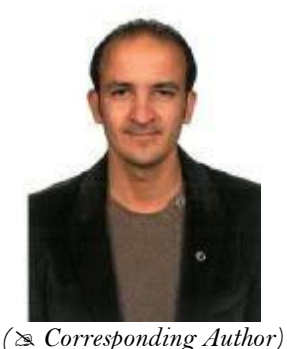

Abstract

The purpose of this study is to analyze the loneliness levels of students studying in 2017-2018 summer school of Balıkesir University School of Physical Education and Sports by some demographic characteristics. This is a descriptive study. The research population is composed of 865 students studying in 2017-2018 summer school of Balıkesir University School of Physical Education and Sports and the sample is composed of randomly selected 348 students. "UCLA Loneliness Scale" adapted into Turkish by Demir (1989) was applied in the study. The overall reliability of the loneliness scale was found to be $\alpha=0.74$. Kolmogorov Smirnov test was evaluated for the conformity of UCLA Loneliness Scale to the normal distribution in data analysis. Since all data were observed not to be normally distributed, Mann Whitney U and Kruskal Wallis tests ranked among the non-parametric tests were performed to compare the loneliness levels. All analyses were performed with SPSS v 17.0 (SPSS Science, Chicago, IL, USA). In conclusion, it has been determined that the loneliness levels of the participants are high $(51.07 \%)$, there is no statistically significant difference by the variables of sex, age, adequate leisure time, recreation and the place of residence while significant differences have been observed by the variables of department, branch and grade.

Keywords: Loneliness, Student, Summer school, Sports, Physical Education, Psychology

Citation | Nahit Ozdayi; Ali Serdar Yücel; Mehmet Burak Demir (2019). Analysis on Loneliness Levels of Students in Summer School of Physical Education and Sports School. Asian Journal of Education and Training, 5(1): 159-165.

History:

Received: 16 November 2018

Revised: 12 December 2018

Accepted: o3 January 2019

Accepted: 23 January 2019

. 21 February 2019

Licensed: This work is licensed under a Creative Commons Attribution 3.0 License $($ (c)

Publisher: Asian Online Journal Publishing Group
Contribution/Acknowledgement: All authors contributed to the conception and design of the study.

Funding: This study received no specific financial support

Competing Interests: The authors declare that they have no conflict of interests.

Transparency: The authors confirm that the manuscript is an honest, accurate, and transparent account of the study was reported, that no vital features of the study have been omitted; and that any discrepancies from the study as planned have been explained.

Ethical: This study follows all ethical practices during writing.

\section{Contents}

1. Introduction

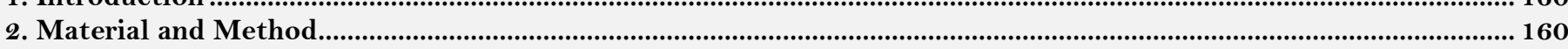

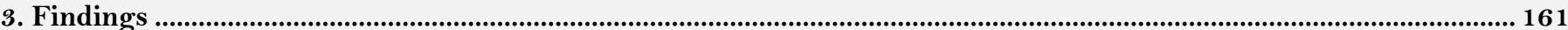

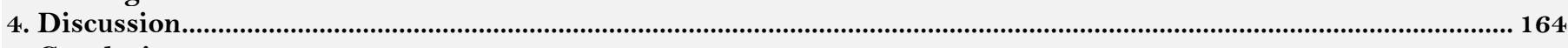

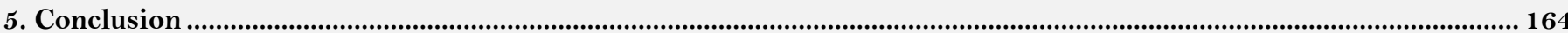

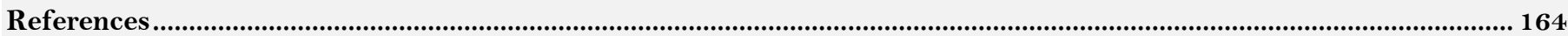




\section{Introduction}

A sport is a very important communication tool that creates an opportunity to establish close relationships. Those who do sports express that they don't experience the phenomenon of loneliness by acquiring a social environment, thus gaining new friendships. A sport is considered as a social behavior that addresses our body and soul. Sport is effective in ensuring the social harmony of the individuals and securing their mental and physical health (Balcıoglu, 2003).

Rogers (2003) states that loneliness is the state that occurs as a result of the inability of an individual to socialize and establish relationships with others.

Social relations are of great importance in people's lives. In recent years, people are said to be unable to make meaningful relationships with other people due to technological developments and rapid industrialization (Saraçoğlu, 2000; Özçelik et al., 2014). Buluş (1996) states that the most important complaints of people are "being alone", "being isolated" and "losing the personality".

Social mobility, the remodeling of sexual roles, mass media and popular trends have led to the emergence of a new and more conscious attitude in many people towards their own bodies. However, the reasons that prompt most people to do sports are not limited to the movement and body. The need to establish a relationship, the fear of being alone, the need to be a social being are as effective as the desire to be athletic and healthy (Baumann, 1994).

When we look at the psychological needs that direct the individual to sports, the socially-attributed motives being among the secondary motives (features such as getting a place in society, being recognized and being a popular person with her/his absence felt among friends) (Kuru, 2000).

Loneliness can be a short-term situational feeling every individual can feel while some people experience this feeling more frequently and this can become a part of her/his personality over time (Imamoglu, 2008). The concepts of loneliness and being alone seem to be different from each other although they bear similarities. While loneliness is generally a condition that disturbs the individual, being alone can be a desired situation (Geçtan, 2004).

\subsection{Types of Loneliness}

A feeling of loneliness basically carries specific characteristics in each individual. Each loneliness experience has its own psychological and human aspect, a specific temporal expansion (Borgna, 2015). Nevertheless, the experiences of loneliness were examined by researchers after classifying them in terms of their qualities and dimensions.

Loneliness was addressed by McWhirter (1990) with the dimensions of interpersonal loneliness, psychological loneliness, social loneliness, cultural loneliness and cosmic loneliness:

Yahyaoglu (2011) analyzed loneliness as deep loneliness, social status loneliness, emotional loneliness, secret loneliness and triad loneliness:

In light of these explanations, the purpose of our study is to analyze the loneliness levels of students studying in School of Physical Education and Sports Summer School by some demographic characteristics. The loneliness levels of students were analyzed in terms of the variables of sex, age, grade, adequate leisure time, sports branch and department.

\section{Material and Method}

\subsection{Research Population and Sample}

In this study, data were obtained by reaching 348 participants among 865 students studying in 2017-2018 summer school of Balıkesir University Physical Education and Sports School.

\subsection{Data Collection}

\subsubsection{UCLA Loneliness Scale}

In order to determine the loneliness level of individuals, Russel, Peplau and Cotrana have revised UCLA Scale (University of California Los Angeles Loneliness Scale) in such a way that half of the items are composed of positive statements while the other half contains negative statements (Demir, 1989).

UCLA loneliness scale is composed of 20 items with straight-coded 10 items and reverse-coded 10 items. The purpose here is to determine how often the participants experience these situations by presenting emotions and/or thoughts about the social relations of the individual with the items of the scale.

This is a 4-point Likert scale. The items with positive statements $(1,4,5,6,9,10,15,16,19,20)$ in the scale are scored as "I never feel this way (4)", "I rarely feel this way (3)", "I sometimes feel this way (2)", "I often feel this way (1)". The items with negative statements $(2,3,7,8,11,12,13,14,17,18)$ are scored as "I never feel this way (1)", "I rarely feel this way (2)", "I sometimes feel this way (3)", "I often feel this way (4)". The highest score that can be obtained from the scale is 80 and the lowest score is 20 . The higher the score is, the higher the loneliness level becomes.

The validity of the scale was found as .50 following its analysis based on "Beck Depression Scale". Demir (1989) found the internal consistency coefficient as .96 in the validity and reliability study. Test retest reliability coefficient of the scale was calculated as .94. In the study of Yildirım (2000) performed on the group of 545 high school students, the reliability coefficient of the scale was .92.

When the analyses related to UCLA loneliness scale have been evaluated, it is seen that UCLA loneliness scale is a valid and reliable measurement tool.

\subsection{Data Analysis}

Kolmogorov Smirnov test was evaluated for the conformity of UCLA Loneliness Scale to the normal distribution in data analysis. Since all data were observed not to be normally distributed, Mann Whitney U and Kruskal Wallis tests were performed to compare the loneliness levels. All analyses were performed with SPSS 
v17.0 (SPSS Science, Chicago, IL, USA). The value of $\mathrm{p}<0.05$ was taken into account while calculating the intergroup statistical differences.

\section{Findings}

Table-1. One-Sample Kolmogorov-Smirnov Normal distribution test results

\begin{tabular}{l|l|c}
\hline \multicolumn{2}{l}{} & UCLA Loneliness Scale \\
\hline $\mathrm{N}$ & Mean & 348 \\
\cline { 2 - 3 } Normal Parameters & Stb & 51.0747 \\
\hline \multirow{2}{*}{ Most Extreme Differences } & Absolute & 6.37901 \\
\cline { 2 - 3 } & Positive & .131 \\
\cline { 2 - 3 } & Negative & .131 \\
\hline Kolmogorov-Smirnov Z & -.047 \\
\hline Asymp. Sig. (2-tailed) & 2.446 \\
\hline Source: Obtained from primary data & .000 \\
\hline
\end{tabular}

The conformity of UCLA Loneliness Scale to the normal distribution was evaluated with Kolmogorov Smirnov test. It is observed that data don't distribute normally (Kolmogorov-Smirnov $\mathrm{Z}=2.446, \mathrm{Sig}=.000, \mathrm{p}<0.05$ ).

Table-2. Man Whitney U Test Statistics - Sex Results

\begin{tabular}{l|c}
\hline & UCLA Loneliness Scale \\
\hline Mann-Whitney U & 14332.000 \\
\hline Wilcoxon W & 28528.000 \\
\hline Z & -.842 \\
\hline Asymp. Sig. (2-tailed) & .400 \\
\hline Source: Obtained from primary data
\end{tabular}

Table-3. UCLA Loneliness Scale Mean Scores by Sex

\begin{tabular}{l|c|c}
\hline & \multicolumn{2}{|c}{ Mean } \\
\hline \multirow{2}{*}{ UCLA Loneliness Scale } & Female & Male \\
\cline { 2 - 3 } & 51.06 & 51.10 \\
\hline Source: Obtained from primary data
\end{tabular}

Hypothesis: Loneliness Level of Participants do not Differ by the Variable of Sex

Mann Whitney U test will be applied to understand whether UCLA loneliness scale differs by sex. Man Whitney $\mathrm{U}$ test result will be used to see if there is any difference between two sexes in terms of responses given to loneliness scale. The main hypothesis of the analysis states that there is no difference between sexes. The probability value (AsympSig) calculated following the test was found to be higher than 0.05. The main hypothesis can't be rejected. Therefore, there is no statistical difference between the results of the responses given by women and men to the UCLA loneliness scale.

Table-4. Kruskal Wallis Test Statistics - Age Results

\begin{tabular}{l|c}
\multicolumn{2}{c}{ Table-4. Kruskal Wallis Test Statistics - Age Results } \\
\hline Chi-square & UCLA Loneliness Scale \\
\hline Df & 2.619 \\
\hline Asymp. Sig. & 2 \\
\hline Source: Obtained from primary data & .270 \\
\hline
\end{tabular}

Table-5. UCLA Loneliness Scale Mean Scores by Age

\begin{tabular}{l|c|c|c}
\multicolumn{4}{c}{ Table-5. UCLA Loneliness Scale Mean Scores by Age } \\
\hline & \multicolumn{3}{|c}{ Mean } \\
\hline \multirow{2}{*}{ UCLA Loneliness Scale } & $17-20$ & $21-25$ & $26-30$ \\
\cline { 2 - 4 } & 51.61 & 51.40 & 49.78 \\
\hline Source: Obtained from primary data
\end{tabular}

Hypothesis: Loneliness Level of Participants do not differ by the Variable of Age

Kruskal Wallis test will be applied to understand whether UCLA loneliness scale differs by age. Kruskal Wallis test result will be used to see if there is any difference between ages in terms of responses given to loneliness scale. The main hypothesis of the analysis states that there is no difference between ages. The probability value (AsympSig) calculated following the test was found to be higher than 0.05. The main hypothesis can't be rejected. Therefore, there is no statistical difference between age groups regarding the responses given to the UCLA loneliness scale.

Table-6. Mann Whitney U Test Statistics - Branch Results

\begin{tabular}{l|c}
\multicolumn{2}{c}{ Table-6. Mann Whitney U Test Statistics - Branch Results } \\
\hline Mann-Whitney U & UCLA Loneliness Scale \\
\hline Wilcoxon W & 11514.500 \\
\hline Z & 26220.500 \\
\hline Asymp. Sig. (2-tailed) & -3.865 \\
\hline Source: Obtained from primary data & .000 \\
\hline
\end{tabular}




\begin{tabular}{l|c|c}
\multicolumn{2}{c}{ Table-7. UCLA Loneliness Scale Mean Scores by Branches } \\
\hline \multirow{2}{*}{ UCLA Loneliness Scale } & \multicolumn{2}{|c}{ Mean } \\
\hline Source: Obtained from primary data & Team Sports & Individual Results \\
\cline { 2 - 3 } & 52.50 & 49.60 \\
\hline
\end{tabular}

Hypothesis: Loneliness Level of Participants do not Differ by the Variable of Branch

Mann Whitney U test will be applied to understand whether UCLA loneliness scale differs by branches. Mann Whitney $\mathrm{U}$ test result will be used to see if there is any difference between branches in terms of responses given to loneliness scale. The main hypothesis of the analysis states that there is no difference between branches. The probability value (AsympSig) calculated following the test was found to be lower than 0.05. The main hypothesis will be rejected. Therefore, there is a statistical difference between branches regarding the responses given to the UCLA loneliness scale. The mean score of answers given by the group engaged in team sports to UCLA loneliness scale was found higher while the score of those engaged in individual sports was found lower.

\begin{tabular}{l|l|c|c}
\hline \multicolumn{2}{l}{ Table-8. Adequate leisure time and recreation results } & Column N \% \\
\hline \multirow{2}{*}{ Adequate leisure time } & Absolutely inadequate & Count & $9.5 \%$ \\
\cline { 2 - 4 } & Inadequate & 33 & $22.1 \%$ \\
\cline { 2 - 4 } & Normally adequate & 77 & $59.8 \%$ \\
\cline { 2 - 4 } & Absolutely adequate & 308 & $8.6 \%$ \\
\hline \multirow{2}{*}{ Recreation } & Always & 32 & $9.2 \%$ \\
\cline { 2 - 4 } & Sometimes & 242 & $69.5 \%$ \\
\cline { 2 - 4 } & Never & 74 & $21.3 \%$ \\
\hline
\end{tabular}

Source: Obtained from primary data

The responses of participants on the adequacy of the weekly leisure time have been evaluated. $9.5 \%$ of the participants state that it is absolutely inadequate, $22.1 \%$ thinks it is inadequate, $59.8 \%$ considers it as normally adequate, $8.6 \%$ expresses that it is absolutely adequate.

As to the question of how often you have difficulty in recreation, $9.2 \%$ of the participants says always, $69.5 \%$ says sometimes and $21.3 \%$ says never.

\begin{tabular}{l|c}
\multicolumn{2}{c}{ Table-9. Kruskal Wallis Test Statistics - Adequate leisure time results } \\
\hline Chi-square & UCLA Loneliness Scale \\
\hline Df & 2.052 \\
\hline Asymp. Sig. & 3 \\
\hline Source: Obtained from primary data & .562 \\
\hline
\end{tabular}

Table-10. UCLA Loneliness Scale Mean Scores by Adequate Leisure Time Responses

\begin{tabular}{l|c|c|c|c}
\hline & \multicolumn{3}{|c}{ Mean } \\
\hline \multirow{2}{*}{ UCLA Loneliness Scale } & Absolutely inadequate & Inadequate & Normally adequate & Absolutely adequate \\
\cline { 2 - 5 } & 51.76 & 50.49 & 51.00 & 52.33 \\
\hline
\end{tabular}

Hypothesis: Loneliness Level of Participants do not Differ by the variable of Adequate Leisure Time

Kruskal Wallis test result will be used to understand whether there are differences between responses given to loneliness scale and responses given to the question of adequate leisure time. The main hypothesis of the analysis states that there is no difference between answers given to the question of adequate leisure time. The probability value (AsympSig) calculated following the test was found to be higher than 0.05 . The main hypothesis can't be rejected. Therefore, there is no statistical difference between responses given to UCLA loneliness scale and responses given to the question of adequate leisure time.

Table-11. Kruskal Wallis Test Statistics - Recreation Results

\begin{tabular}{l|c}
\hline & UCLA Loneliness Scale \\
\hline Chi-square & 1.411 \\
\hline Df & 2 \\
\hline Asymp. Sig. & .494 \\
\hline Source: Obtained from primary data
\end{tabular}

Table-12. UCLA Loneliness Scale Mean Scores by Recreation

\begin{tabular}{l|c|c|c}
\hline \multicolumn{3}{|c}{ Mean } \\
\hline \multirow{2}{*}{ UCLA Loneliness Scale } & Always & Sometimes & Never \\
\cline { 2 - 4 } & 51.69 & 50.92 & 51.32 \\
\hline Source: Obtained from primary data
\end{tabular}

Source: Obtained from primary data

Hypothesis: Loneliness Level of Participants do not Differ by the Variable of Recreation

Kruskal Wallis test will be applied to understand whether UCLA loneliness scale differs by the answers on recreation. Kruskal Wallis test result will be used to understand whether there are differences between responses given to loneliness scale and responses given to the question of recreation. The main hypothesis of the analysis states that there is no difference between answers given to the question of recreation. The probability value (AsympSig) calculated following the test was found to be higher than 0.05. The main hypothesis can't be rejected. 
Therefore, there is no statistical difference between responses given to UCLA loneliness scale and responses given to the question of recreation.

Table-13. Kruskal Wallis Test Statistics - Department Results

\begin{tabular}{l|c}
\hline & UCLA Loneliness Scale \\
\hline Chi-square & 8.473 \\
\hline Df & 2 \\
\hline Asymp. Sig. & .014 \\
\hline Source: Obtained from primary data
\end{tabular}

Table-14. UCLA Loneliness Scale Mean Scores by Departments

\begin{tabular}{l|c|c|c}
\hline & \multicolumn{3}{|c}{ Mean } \\
\hline \multirow{2}{*}{ UCLA Loneliness Scale } & Physical Education and Sports Teaching & Sports Management & Coaching Education \\
\cline { 2 - 4 } & 50,26 & 52,14 & 50,57 \\
\hline
\end{tabular}

Hypothesis: Loneliness Level of Participants do not Differ by the Variable of Department

Kruskal Wallis test will be applied to understand whether UCLA loneliness scale differs by departments. Kruskal Wallis test result will be used to understand whether there are differences between departments in terms of answers given to the loneliness scale. The main hypothesis of the analysis states that there is no difference between departments. The probability value (AsympSig) calculated following the test was found to be lower than 0.05. The main hypothesis will be rejected. Therefore, there is a statistical difference between departments in terms of responses given to UCLA loneliness scale. While the mean scores of responses given by the participants studying in Sports Management to the UCLA loneliness scale are higher, the mean scores of the participants studying in physical education and sports teaching department are the lowest.

\begin{tabular}{l|c}
\multicolumn{2}{c}{ Table-15. Kruskal Wallis Test Statistics - Grade Results } \\
\hline Chi-square & UCLA Loneliness Scale \\
\hline Df & 17.163 \\
\hline Asymp. Sig. & 3 \\
\hline Source: Obtained from primary data & .001 \\
\hline
\end{tabular}

Table-16. UCLA Loneliness Scale Mean Scores by Grades

\begin{tabular}{l|c|c|c|c}
\hline & \multicolumn{4}{|c}{ Mean } \\
\hline \multirow{2}{*}{ UCLA Loneliness Scale } & 1 & 2 & 3 & 4 \\
\cline { 2 - 5 } & 46.00 & 47.50 & 50.49 & 51.91 \\
\hline
\end{tabular}

Hypothesis: Loneliness Level of Participants do not Differ by the Variable of Grade

Kruskal Wallis test will be applied to understand whether UCLA loneliness scale differs by grades. Kruskal Wallis test result will be used to understand whether there are differences between grades in terms of answers given to the loneliness scale. The main hypothesis of the analysis states that there is no difference between grades. The probability value (AsympSig) calculated following the test was found to be lower than 0.05. The main hypothesis will be rejected. Therefore, there is a statistical difference between grades in terms of responses given to UCLA loneliness scale. The mean score of answers given by the fourth grade participants to the UCLA loneliness scale is higher while the mean scores of first grade students are the lowest.

\begin{tabular}{l|c}
\multicolumn{2}{c}{ Table 17. Kruskal Wallis Test Statistics - Place of Residence Results } \\
\hline Chi-square & UCLA Loneliness Scale \\
\hline Df & 1.247 \\
\hline Asymp. Sig. & 2 \\
\hline Source: Obtained from primary data
\end{tabular}

Table-18. UCLA Loneliness Scale Mean Scores by Place of Residence

\begin{tabular}{l|c|c|c}
\hline & \multicolumn{3}{|c}{ Mean } \\
\hline \multirow{2}{*}{ UCLA Loneliness Scale } & Dormitory & With Family & Student house \\
\cline { 2 - 4 } & 51.06 & 51.04 & 51.10 \\
\hline Source: Obtained from primary data
\end{tabular}

Hypothesis: Loneliness Level of Participants do not Differ by the Variable of Place of Residence

Kruskal Wallis test will be applied to understand whether UCLA loneliness scale differs by place of residence. Kruskal Wallis test result will be used to understand whether there are differences between places of residence in terms of answers given to the loneliness scale. The main hypothesis of the analysis states that there is no difference between places of residence. The probability value (AsympSig) calculated following the test was found to be higher than 0.05. The main hypothesis can't be rejected. Therefore, there is no statistical difference between places of residence in terms of responses given to UCLA loneliness scale. 


\section{Discussion}

In this study aiming to analyze the loneliness levels of students studying in 2017-2018 summer school of Balıkesir University School of Physical Education and Sports by some demographic characteristics, no statistically significant difference has been found between the loneliness levels of students by the variable of $\operatorname{sex}(\mathrm{p}>0.05)$. In the study of Ceçen (2008) examining "loneliness and social support levels of university students by their sex and attitude perception of parents", it has been expressed that loneliness levels don't differ by the main effect of sex, female and male students have similar loneliness perceptions.

Looking at loneliness scale scores by the variable of age, it is highest in the students of 17-20 age group (mean 51.61 ). They are followed by people in 21-25 age group (mean 51.40) and in 26-30 age group (mean 49.78). We can say that there is an inverse relationship between age increase and loneliness level. In a study analyzing the effect of age on loneliness level, Koçak (2008) has quoted that loneliness is most common in adolescence. In a research conducted by Steptoe et al. (2004) on working women and men at the age of 47-59, they haven't established a relation between loneliness and age.

When the UCLA loneliness scale results are compared in terms of the branches, the scores of the team sports group are higher than those engaged in individual sports. In other words, the loneliness perception of those engaged in team sports is higher. This result hasn't been supported with the relevant literature. In the book of Kuru (2000) compiling the researches conducted regarding personality traits and sports branches, the athletes of team sports have been stated to be more extrovert, outgoing and socially compatible individuals. The athletes of individual sports are expressed to be more introvert and closed with an emphasis on the sense of belonging and on the pleasure provided by self-realization and proving that they have succeeded this on their own. In the study of Morgan (1999) the athletes of individual sports have more positive personality traits; however, there is no difference between their loneliness levels. In another similar study performed by Sheykh et al. (2006) loneliness levels of 100 athletes of individuals sports and 100 basketball players have been compared and no significant difference has been observed.

Considering the responses of the participants about the adequacy of weekly leisure time, $8.6 \%$ of the participants (mean: 52.33) have stated that it is absolutely adequate. The loneliness scale mean scores of the group stating that leisure time is absolutely adequate have been found to be higher than other participants. Namely, the students with adequate leisure time are more alone. Analyzing the UCLA loneliness scale scores by the variable of department, a statistically significant difference has been observed between them. While the mean responses given by the participants studying in sports management to the UCLA loneliness scale are higher, the mean scores of the participants studying in physical education and sports teaching are the lowest. Low loneliness scores of students studying in physical education and sports department indicate that these students are self-confident, friendly and social individuals who act in accordance with the environment in social situations, can empathize and interpret the feelings of others accurately and fully, have the skills of initiating and directing conversations in any subject as defined in the study of Avşar (2004) titled determining the social skill levels of physical education and sports students.

There is a statistical difference between UCLA loneliness scale scores by the variable of grade. The mean score of answers given by the fourth grade students to the UCLA loneliness scale is higher while the mean scores of first grade students are the lowest. In other words, the loneliness perception of fourth grade students is higher. The fact that the fourth grade students are about to graduate and the stress they feel about employment may be the reason they feel alone.

\section{Conclusion}

In conclusion, it has been determined that loneliness levels of the participants (51.07\%) are high and no statistically significant difference exists by the variables of sex, age, adequate leisure time, recreation and place of residence. $59.8 \%$ of the participants state that their leisure time is adequate while $69.5 \%$ have stated to have problems in making use of their leisure time from time to time. Looking at the mean scores of answers given to UCLA scale, it has been determined that the highest scores belong to those studying in sports management by the variable of department, to the participants engaged in team sports by the variable of branch and to the fourth grade students by the variable of grade.

\section{References}

Avşar, Z., 2004. Determination of social skills levels of physical education and sport teachers. Journal of Faculty of Education, 17(2): 111130 .

Balcıŏlu, İ., 2003. Sociology and psychology of sport. Istanbul: Bilge Publications.

Baumann, S., 1994. Applied sports psychology. (Translated by C. İkizler, O.A. Özcan). Istanbul: Alfa Publishing Publishing.

Borgna, E., 2015. Solitude of the soul. (Translated by Meryem Mine Çilingiroğlu). Istanbul: Yapı Kredi Publications.

Buluş, E.M., 1996. The relationship between locus of control and loneliness level. Dokuz Eylul University, Izmir, Unpublished Master Uns Thesis.

Ceçen, A.R., 2008. Examination of loneliness and social support levels of students according to their gender and parental attitudes. Turkish Journal of Educational Sciences, 6(3): 415-431.

Demir, A., 1989. In validity and reliability of UCLA loneliness scale. Journal of Psychology, 7(23): 14-18.

Geçtan, E., 2004. Being human. Istanbul: Metis Publications.

Imamoglu, S., 2008. An investigation of interpersonal relations in terms of gender, gender roles and loneliness perception in young adulthood. Unpublished PhD Thesis. Istanbul: Marmara University Institute of Educational Sciences. pp: 9.

Koçak, E., 2008. Self-esteem and trait anger and expression of anger expression as a predictor of loneliness in adolescents. Unpublished Master Socials Thesis, Cukurova University Institute of Social Sciences, Adana. pp: 3.

Kuru, E., 2000. Psychology in sport. Ankara: Gazi University Faculty of Communication Publishing.

McWhirter, B.T., 1990. Loneliness: A review of current literature, with implications for counseling and research. Journal of Counseling \& Development, 68(4): 417-422. Available at: https://doi.org/10.1002/j.1556-6676.1990.tb02521.x.

Morgan, W.P., 1999. Psychological outcomes of physical activity. Basic and Applied Sciences for Sport Medicine, 24: $273-279$.

Özçelik, Y.I., O. Imamoglu, R. Çekin and B.S. Gölünük, 2014. The effect of sports on the university students' level of loneliness. Journal of Sports and Performance Researches, 6(1): 12-18. Available at: 10.17155/spd.18840.

Rogers, C., 2003. Interaction groups. (Translated by H. Erbil). Ankara: Doruk Publishing. 
Saraçoğlu, Y., 2000. Examination of high school students' loneliness levels according to various variables. Ondokuz Mayıs University, Unpublished Masterps Thesis, Samsun.

Sheykh, M., B. Yousefi, Z. Hasani and F. Zivyar, 2006. Assessment and comparison of control resources (internal - external) and feeling of loneliness among female athletes and non-athletes. Research on Sport Science, 10: 125-135.

Steptoe, A., N. Owen, E.S. Kunz and L. Brydon, 2004. Loneliness and neuroendocrine, cardiovascular, and inflammatory stress responses in middle-aged men and women. Psychoneuroendocrino, 29(5): 593- 611. Available at: https://doi.org/10.1016/s03064530(03)00086-6.

Yahyaoglu, R., 2011. Psychology of loneliness. 7th Edn., İstanbul: Nesil Yayınları.

Yıldırım, İ., 2000. Loneliness as a predictor of academic success, exam anxiety and social support. Journal of Hacettepe University Faculty of Education, 18: 167-176. 